\title{
A POLÍTICA DE COTAS RACIAIS E AS MUDANÇAS NA PRÁTICA PEDAGÓGICA \\ http://dx.doi.org/10.5902/2318133816840
}

\author{
Carmen Terezinha Maciel Alende \\ Universidade Federal do Pampa, campus Alegrete, Brasil. \\ Mário Augusto Correia San Segundo \\ Universidade Federal do Pampa, campus Alegrete, Brasil.
}

\begin{abstract}
Resumo
Este estudo teve como objetivo identificar as mudanças na prática pedagógica após a implantação da política de cotas raciais, com ênfase na população negra em um curso técnico. Trata-se de pesquisa qualitativa exploratória, desenvolvida com sete professores. Como práticas pedagógicas que contribuem para a implantação do sistema de cotas raciais, evidenciaram-se as metodologias ativas de ensino e a leitura de materiais acadêmico-científicos. Como práticas que desfavorecem a implantação da política estão a postura do docente e o modelo convencional/tradicional de ensino. Sugere-se a formação continuada dos docentes como estratégia que pode auxiliar para um repensar coletivo dos professores, atentando para as questões étnico-raciais e construindo uma prática pedagógica contextualizada.

Palavras-chave: política de cotas, ensino, práticas pedagógicas.
\end{abstract}

\section{THE POLICY OF RACIAL QUOTAS AND CHANGES IN PEDAGOGICAL PRACTICE}

\begin{abstract}
This study aimed to identify changes in pedagogical practice after the implementation of the policy of racial quotas, with emphasis on the black population, in a technical course. Exploratory qualitative research, developed with seven teachers. As pedagogical practices that contribute to the implementation of the system of racial quotas, showed the active teaching methodologies and the reading of academic and scientific materials. As practices that handicaps the implementation of the policy are the posture of the teacher and the conventional/traditional teaching model. It is suggested the continuing training of teachers as a strategy that can assist to a collective rethinking of all educators, paying attention to ethnic and racial issues and building a pedagogical practice contextualized.
\end{abstract}

Key-words: quota politics, teaching, pedagogical practices. 


\section{Introdução}

s cotas raciais no Brasil surgiram a partir da necessidade de aumentar o
acesso da população negra em todos os níveis de escolaridade, sendo
assim, no início do século 21, várias instituições de ensino superior brasileiras passaram a adotar as denominadas ações afirmativas para negros e indígenas, com ênfase no sistema de cotas.

As ações afirmativas compreendem os programas e medidas especiais adotados pelo Estado e pela iniciativa privada para a correção das desigualdades raciais e para a promoção da igualdade de oportunidades (Brasil, 2010).

Nesse contexto, são notórios os elevados índices de desigualdade racial e social presentes na relação entre brancos e negros. Em relação ao emprego formal, por exemplo, verificou-se que, no ano de 2009, os homens brancos possuíam o maior índice de formalização, totalizado $43 \%$ com carteira assinada, enquanto que as mulheres negras se apresentam $25 \%$ com carteira assinada (Ipea, 2011).

Em se tratando da taxa de escolarização líquida no ensino superior, que mede a proporção de pessoas matriculadas no nível de ensino adequado para sua idade, era de $5,8 \%$ no ano de 1995 , chegando, em 2009 , a $14,4 \%$. Neste mesmo ano, esta taxa era de $21,3 \%$ entre a população branca, contra apenas $8,3 \%$ entre a população negra, chegando a apenas $6,9 \%$ entre os homens negros. Em 2009, a taxa de escolarização das mulheres no ensino superior era de $16,6 \%$, enquanto a dos homens, de $12,2 \%$. A taxa de escolarização de mulheres brancas no ensino superior é de $23,8 \%$, enquanto, entre as mulheres negras, esta taxa é de apenas $9,9 \%$ (Ipea, 2011, p. 21). Ademais, destaca-se que, dentro do cenário docente, em cem anos de vida universitária, a população negra é representada por $1 \%$ (Domingues, 2005).

Em 2012 foi criada a lei federal n. 12.711, que instituiu o ingresso de autodeclarados pretos, pardos e indígenas em universidades federais e nas instituições federais de ensino técnico de nível médio (Brasil, 2012). Com esta lei diversas instituições passaram a adotar as políticas e ações afirmativas, no intuito de viabilizar uma inclusão mais ampla para a população negra (Brasil, 2011).

Apesar desta lei e da ampliação dos espaços de ensino para a população negra, considera-se que a pluralidade existente na sociedade deve desafiar 0 docente a repensar, reorganizar e reestruturar sua práxis. Portanto, a heterogeneidade do grupo deve representar um desafio à criatividade do docente, capaz de gerar e gerir mudanças de concepções, políticas e práticas educativas (Sanches, Teodoro, 2006).

Desse modo, a questão que norteou este estudo foi: quais foram as mudanças na prática pedagógica após a implantação da política de cotas raciais, com ênfase na população negra? O objetivo foi identificar as mudanças na prática pedagógica após a implantação da política de cotas raciais, com ênfase na população negra, em um curso técnico.

\section{Revisão de literatura}

Coerente com o objetivo deste estudo apresenta-se, nesta revisão, os seguintes conceitos: inclusão social, inclusão escolar, educação inclusiva, população negra e a educação. Assim, destaca-se, inicialmente, o termo inclusão social como a possibilidade de tornar o indivíduo participante da vida social, econômica e política, assegurando-Ihe o 
respeito aos seus direitos. Nesse processo, a sociedade se adapta para permitir a participação dos indivíduos em todos os setores, preparando-lhes para assumir seus papéis na sociedade (Araújo, Schmidt, 2006).

No âmbito escolar, a inclusão busca superar as situações de exclusão, garantindo o direito de todo e qualquer sujeito em ter a oportunidade de aprender e participar dentro da escola, sem nenhum tipo de discriminação. Dessa forma, a inclusão escolar "tem como objetivo a construção de uma escola acolhedora" (Brasil, 2006, p. 15). Logo, entende-se que a escola deve se preparar para acolher o ser humano tal como ele é, sem fragmentálo para torná-lo igual aos demais (Alves, Canterle, 2011). Para isso, é imprescindível que a escola auxilie os docentes, os capacitando, preparando, organizando e adaptando (Glat, Fernandes, 2005).

Considerando uma interface entre a educação inclusiva e a população negra, esta primeira considera que ninguém deve ser segregado porque apresenta deficiência, dificuldade de aprendizagem ou devido ao seu gênero ou por pertencer a uma minoria étnico racial (Sánchez, 2005). Em se tratando especificamente da população negra, entende-se que a atual condição de desigualdade que este grupo se encontra seja reflexo histórico de um país que, além de ser o último do mundo a abolir a escravidão, perpetuou a discriminação racial e o racismo. Nessa perspectiva, a população negra é aquela que possui os piores níveis de escolaridade, as maiores dificuldades para ingresso no mercado de trabalho e, no momento em que esta é inserida neste, ocupa as mais desvalorizadas funções, aspectos estes que só aumentam a sua condição de vulnerabilidade (Unicef, 2011). Corroborando com isso, dados estatísticos do IBGE apontam que o acesso à educação, à moradia, à saúde e ao emprego é consideravelmente menor para a população negra (Amorim, 2011). Por exemplo, em relação à escolaridade, "enquanto os adolescentes de 15 a 17 anos brancos atingem 7,8 anos de estudo, em média, os indígenas têm 7 e os negros, 6,8" (Unicef, 2011, p. 51).

Quando se refere ao ensino médio, os dados demonstram que na rede pública, durante um ano letivo, aproximadamente um milhão de estudantes abandonam a escola. Estaticamente isso equivale a $16,9 \%$ das matrículas. Em se tratando da rede privada, a evasão escolar não chega a $3 \%$ e quando se considera em nível nacional, incluindo as duas redes, a taxa de abandono escolar é de 15\% (Inep, 2001). Somando-se a estes números, quando é analisada a raça do estudante, percebe-se que, no ensino médio, o índice de jovens brancos de 15 a 17 anos que frequentam a escola é de $62 \%$, sendo que na população negra esses valores caem pela metade. Considerando um recorte etário de 19 anos, os brancos possuem uma taxa de conclusão do ensino médio de 55\%, enquanto que entre os negros essa taxa é de 33\% (Brasil, 2009).

Nesse sentido, a inserção da população negra no cenário educacional tem seu início a partir dos anos 1980, com a Constituinte e a elaboração da nova Lei de Diretrizes e Bases da Educação, as quais tiveram participação do movimento negro. A seguir, na década de 1990, a militância negra passou a reivindicar a inclusão da questão racial no interior das políticas públicas universais, destacando a educação como um direito à diversidade étnico-racial. É nesse contexto que as ações afirmativas surgiram como uma demanda política que, posteriormente, em 2003, transformou-se em ações concretas (Gomes, 2011). 
Na sequência, ainda foi criada a Secretaria Especial de Promoção da Igualdade Racial, em 2003, e a Secretaria de Educação Continuada, Alfabetização e Diversidade, no ano de 2004 (Gomes, 2011). Entretanto, como

a história política brasileira nos revela que entre as intenções das legislações antirracistas e a sua efetivação na realidade social há sempre distâncias, avanços e limites, os quais precisam ser acompanhados pelos cidadãos e cidadãs brasileiros e pelos movimentos sociais por meio por um efetivo controle público. (Gomes, 2011, p. 115)

Assim, apesar dos inegáveis avanços possibilitados com a criação da política de cotas raciais, é essencial questionar a real implantação desta na prática pedagógica dos docentes. Destaca-se que, nesse estudo, prática pedagógica consiste em todas as ações do docente no espaço de sala de aula (Tozetto, Gomes, 2009).

\section{Método}

Trata-se de uma pesquisa com abordagem qualitativa do tipo exploratória. Entendese que, tanto a abordagem qualitativa, quanto o tipo exploratório permitem uma visão geral do fenômeno na perspectiva dos sujeitos estudados, trabalhando com os significados, aspirações, crenças, valores e atitudes dos mesmos (Gil, 2007).

$O$ estudo foi realizado em uma instituição que dispõe de um curso técnico e que encontra-se localizada no interior do Rio Grande do Sul, nos meses de julho e agosto de 2014. Os sujeitos do estudo foram docentes atuantes no Curso Técnico de Agropecuária. Foi adotado como critério de inclusão no estudo ser professor, de ambos os sexos, em exercício profissional na instituição.

Inicialmente foi realizado contato com a Instituição, a fim de identificar os professores atuantes no referido curso. Mediante a identificação destes sujeitos foi realizado convite verbal individual a todos para participação no estudo. Entretanto, apenas sete manifestaram interesse em participar, o que equivale a aproximadamente $20 \%$ do corpo docente do curso. Com estes, foi realizada uma entrevista semiestruturada.

A entrevista semiestruturada consiste em um tipo de entrevista na qual sé utilizado um roteiro que norteia a mesma. Assim, entrevistado e pesquisador discorrem acerca do tema em foco a partir de indagações feitas pelo pesquisador (Gil, 2007). Para atender a questão do anonimato, foi viabilizada a identificação dos docentes por meio do sistema alfanumérico, identificado pela letra "P", de professor, e ordenação numérica: 1, 2, 3 e assim sucessivamente.

Para análise, interpretação e apresentação dos dados foi realizada a seleção, simplificação, abstração e transformação dos dados. A seguir foi realizada a organização do material, identificando as ideias mais expressivas nos depoimentos dos participantes. Por fim, foi realizada a interpretação das entrevistas realizadas, considerando os pressupostos teóricos acerca do tema. Nesse sentido, foram identificadas as convergências, as divergências e as semelhanças existentes entre os depoimentos dos participantes, confrontando com diferentes referenciais teóricos da educação. 


\section{Resultados e discussão}

Os sete docentes entrevistados apresentavam faixa etária entre os 27 e 56 anos de idade. Cinco eram do sexo masculino e dois do sexo feminino. Em se tratando da escolaridade, quatro declararam ter graduação, um especialização e dois possuíam mestrado.

Ao questionar a concepção dos entrevistados acerca da política de cotas raciais, estes apresentaram algumas ponderações em relação ao tema, conforme se evidencia nas afirmações, a seguir:

"Concepção positiva referente a cotas raciais, pois oportuniza e resgata um pouco das injustiças e preconceitos raciais que perduraram e perduram ainda nos dias atuais, por séculos no nosso país oportunamente a todos." (P1)

"Estou de acordo, visto que é uma forma de oportunizar a igualdade entre as classes. E é hipocrisia, senão reconhecermos que a maioria dos negros e dos índios não estão incluídos entre os favorecidos." (P3)

"As cotas raciais são uma ação compensatória do estado, inserida no contexto brasileiro como outras existentes, que buscam compensar as distorções econômicas, que desagregaram e desagregam as classes sociais no Brasil. $O$ direito à propriedade privada, à abolição da escravatura e o trabalho assalariado no desenvolvimento inicial do capitalismo no período colonial foram marcantes para estabelecer as diferenças sociais e econômicas dos brasileiros, atualmente. Há mais de um século, os efeitos desagregadores do capitalismo impossibilitaram o acesso à educação das classes sociais subalternas, principalmente para os negros, pardos, que viveram o pré-capitalismo brasileiro, como escravos das sesmarias. E, até hoje, são marcados pela herança do racismo, pré-conceitos e estigmas que perduram na sociedade contemporânea. Portanto, a política de cotas é uma ação mínima de procurar promover a inclusão a um dos direitos básicos constitucionais, entre outros, de toda a população." (P7)

Embora tenha sido questionada apenas a concepção em relação à política, percebese que os entrevistados manifestam mais que suas percepções, também relevam seus posicionamentos acerca do assunto. Assim, verifica-se que estes docentes são favoráveis à política e a relacionam com uma forma de justiça e igualdade, assim como um tipo de compensação pela dívida social com a população negra. Assim, o sistema de cotas para negros apresenta-se, nestes depoimentos, como uma forma de reparação, pois, para estes docentes, a educação é um meio de transformação social (UFBA, 2005).

Corroborando com estes depoimentos, outro estudo (Emerich, 2011) também identificou posicionamentos favoráveis entre docentes de um curso de Pedagogia, os quais destacaram como uma das justificativas para a existência de um sistema de cotas o fato de a população negra possuir as menores oportunidades não só na educação, como em todos os segmentos da sociedade, dentre as quais, evidenciam-se as dificuldades de acesso à educação, lazer e saúde, assim como as precárias condições de saneamento básico, a menor expectativa de vida, os altos índices de mortalidade infantil, a distribuição desigual de renda e de bens culturais, entre outras iniquidades (Santos, Siman, 2008).

É importante ressaltar os argumentos levantados pelos docentes, dos quais merece destaque àqueles que dizem respeito à reparação pelas injustiças causadas à população 
negra. Visto que a partir dessa concepção, vislumbra-se a política de cotas raciais como um direito social destinado a indivíduos que, ao longo da história, foram excluídos do acesso à educação. Sob essa perspectiva, o sistema de cotas raciais representaria a democratização do acesso à educação (Emerich, 2011; Emerich, 2012). Ademais, enfatiza-se que este argumento também foi identificado em um estudo (Santos, Siman, 2008) realizado com um grupo de professores de uma rede pública de ensino.

Contrariamente ao posicionamento destes, outros docentes mostraram-se desfavoráveis ao sistema de cotas, por considerarem, entre outros aspectos, que este promove a desigualdade numa sociedade igualitária, conforme se percebe no relato a seguir de um dos entrevistados:

"Cotas raciais, na minha opinião, é uma desigualdade na sociedade, partindo do princípio que somos todos iguais. Todos nós somos capazes de qualquer coisa, inclusive o acesso gratuito dos estudos. Se fosse comprovado cientificamente que negros e pardos tivessem alguma dificuldade ou deficiência no aprendizado, poderia ser justo a cota racial. Caso contrário, é uma desigualdade com àqueles que se dedicaram integralmente para conseguir uma vaga." (P2)

Além deste, outro docente afirmou que considerava a política de cotas raciais como uma estratégia desnecessária. Nessa linha, autores (Queiroz, Santos, 2006) também identificaram posições contrárias de professores ao sistema de cotas para negros em uma universidade federal. Segundo estes autores seus entrevistados consideravam que o sistema representa uma forma de oficializar o racismo e que os cotistas vivenciam dificuldades na realização do curso. Nesse sentido, percebe-se que, embora também contrários à política, os argumentos levantados pelos entrevistados do estudo de Queiroz e Santos (2006) diferem daqueles apresentados pelos docentes do presente estudo.

Em relação aos docentes que se posicionaram de maneira contrária, a literatura (Bayma, 2012) esclarece que essa percepção é levantada por aqueles que consideram que o sistema de cotas raciais pode levar à discriminação e aumentar o racismo, pois incitaria o ódio entre as raças. Além disso, estes consideram que as cotas poderiam contribuir para a inferiorização do negro na sociedade, favorecendo ainda mais o preconceito, ao invés de combatê-lo (Santos, Siman, 2008). Contudo, àqueles que apoiam a implantação das ações afirmativas afirmam que não veem problemas, caso esta estratégia contribua para criação de conflitos nas relações raciais, visto que esse pode ser o primeiro passo para superar definitivamente o racismo (Domingues, 2005).

Frente às considerações desfavoráveis identificadas nos depoimentos, Domingues (2005) ainda destaca que a oposição às cotas raciais, sem apresentar nenhuma outra alternativa para eliminar as desigualdades de oportunidades vivenciadas pela população negra no âmbito educacional, é assumir a posição de opressão e posicionar-se a favor da exclusão e do racismo.

Além destes relatos favoráveis ou contrários, pode-se verificar que um dos docentes não assumiu sua posição quanto à política, apenas trouxe algumas considerações:

"A política de cotas está no seu início, ainda resta muito a ser aprimorado, principalmente a ênfase nas cotas sociais, baseadas na renda do indivíduo. A política de cotas raciais é uma conquista dos movimentos sociais, movimento negro principalmente, que por meio de sua articulação 
com o governo veio a ser implementada, onde atualmente enfrenta reações positivas e negativas da sociedade." (P5)

Depreende-se que um posicionamento favorável ou desfavorável acerca da temática não é uma questão relativamente simples, visto que neste estão imbricadas questões sociais, culturais, históricas e políticas. Desse modo, enfatiza-se que a percepção em relação ao sistema de cotas raciais deve ser construída a partir de uma reflexão aprofundada sobre as ações afirmativas, e não apenas considerando aspectos ideológicos, que desconsideram a existência de uma pluralidade étnico racial (Emerich, 2011).

A seguir, além das concepções, também foram questionadas as práticas pedagógicas que, no ponto de vista dos docentes, aproximavam-se e/ou distanciavam-se da política das cotas raciais. Abaixo se apresentam algumas ponderações feitas durante as entrevistas:

"As práticas pedagógicas utilizadas, atualmente, não se aproximam e/ou se distanciam, visto que são as mesmas utilizadas antes das cotas." (P1)

"Acredito que as práticas pedagógicas não interferem na política das cotas raciais, uma vez que as práticas pedagógicas são desenvolvidas dentro da instituição de ensino, diretamente em cima dos alunos." (P2)

"Em alguns casos, a leitura de textos, artigos problematizados por membros atuantes na política de cotas podem esclarecer dúvida. Em outros, a visão pragmática do educador pode refletir situações negativas, senão for bem argumentada e embasada em dados qualitativos, principalmente." (P5)

"Não conheço." (P6)

"Algumas práticas pedagógicas mesmo sem objetivos diretos para promover uma aproximação das cotas raciais podem estar em sintonia com a mesma, principalmente, quando os educadores promovem metodologias participativas, com base nas pedagogias construtivistas, ao contrário dos métodos tradicionais da chamada escola bancária, difusionista, instituída no Brasil para implantar o modelo técnico industrial produtivista, e utilizados ainda em muitas escolas de nível superior." (P7)

Mediante a análise destas afirmações percebe-se que, alguns docentes, não consideram que o sistema de cotas raciais possa refletir sobre as práticas pedagógicas. Outros, ao contrário, citam práticas que podem contribuir ou desfavorecer a implantação da política. Entre as práticas que se aproximam, destacam as metodologias ativas de ensino e a utilização de algumas estratégias, como a leitura de materiais acadêmicocientíficos. Já como práticas que se distanciam estão a postura do docente, além do modelo convencional/tradicional de ensino.

Destaca-se, principalmente, o depoimento de um dos depoentes que afirma que "a visão pragmática do educador pode refletir situações negativas” (P5), a qual vai ao encontro das considerações feitas por Akkari e Santiago (2010):

Nas ações cotidianas de ensino-aprendizagem nas escolas e no processo de formação docente, prevalece o monoculturalismo curricular, que 
transforma diferença em desigualdade, naturalizando preconceitos e esterótipos, que se traduzem no insucesso escolar (p. 28).

Além disso, os docentes também foram questionados se após o advento da política haviam realizado modificações em suas práticas pedagógicas. Nesse contexto, ressaltase que nenhum destes referiu ter desenvolvido qualquer alteração em sua prática:

"Não, pois uma vez selecionado para ingressar na instituição provou que tem conhecimento adequado para se tornar um aluno, seja ele branco ou negro." (P2)

"Não. Sempre defendi o direito igualitário na educação ou em qualquer outro aspecto. Isto no sentido de classes, raças, orientação sexual, etc. e para isso, como docente, me utilizo do discurso em sala de aula da mesma forma que antes." (P3)

"Não. Os assuntos continuam sendo abordados da mesma forma dentro dos conteúdos, quando surgem dentro dos conteúdos os alunos têm diálogo aberto, respeitando as opiniões de todos, desde que embasadas." (P5)

"Não, pois as práticas pedagógicas que exerço buscam promover o diálogo permanente entre o educador $e$ os educandos, valorizando a contextualização da realidade social, econômica, ambiental, humana, ética, política, cultural, ou seja, com análise de diversas dimensões e abordando as causas da desigualdade e diferenciação social como proposta libertadora para promover a construção dos educando como sujeitos históricos, passíveis de interagirem como indutores de mudanças e transformações da realidade." (P7)

Entre as justificativas apontadas pelos participantes do estudo para não modificarem suas práticas pedagógicas percebe-se que alguns não as fizeram por não considerarem necessário. Enquanto outros referiram que apresentavam uma prática docente pautada no diálogo e que, por isso, não modificar ou rever sua práxis docente.

Corroborando os depoimentos dos entrevistados, a literatura (Cordeiro, 2012) elucida que ainda são escassas as mudanças no tocante às práticas pedagógicas. Além disso, a mesma autora destaca que quando estas práticas estão presentes, costumam resultar da pressão de pesquisadores de temáticas étnico-raciais, que desencadeiam a inserção de disciplinas, linhas de pesquisa, eventos, políticas de apoio aos cotistas, discussões em meio acadêmico, entre outros.

Entretanto, diferentemente do que foi exposto pelos entrevistados, depreende-se que a implantação do sistema de cotas raciais deveria instigar os docentes para a necessidade de repensar, reorganizar, ressignificar e reestruturar os seus cenários de atuação. Portanto, na tentativa de atender a todos indistintamente e de incorporar a pluralidade no contexto educacional, faz-se necessário a transformação do cotidiano de ensino e das práticas pedagógicas. Caso contrário, corroborando com as considerações de Gomes (2011), acredita-se que a educação irá contribuir para a produção e reprodução de um quadro de desigualdades raciais.

$\mathrm{Na}$ literatura foram identificadas algumas práticas pedagógicas voltadas para a diversidade étnico-racial, entre elas, trabalhos com a comunidade, movimento negro e comunidades terreiro, além de projetos interdisciplinares, atividades no Dia Nacional da 
Consciência Negra, estudos sistemáticos sobre o continente africano e projetos realizados com a participação dos estudantes (Gomes, 2011).

Entretanto, conforme destaca Gomes (2005, p. 146) "ainda encontramos muitos educadores que pensam que discutir sobre relações raciais não é tarefa da educação". Nesse sentido, acredita-se que trabalhar essas questões no ambiente educacional não é transformar esses temas em conteúdos escolares, mas levar em consideração a formação histórica e cultural da sociedade brasileira e valorizar a diversidade étnicocultural existe nesta (Gomes, 2005).

Por fim, ainda questionou-se se houve mudanças no Curso Técnico de Agropecuária com o advento da política de cotas raciais e estas refletiram na prática pedagógica dos docentes do Curso. As percepções dos entrevistados podem ser verificadas, a seguir.

\section{“Nenhuma alteração.” (P1)}

"Apesar de estar trabalhando pouco mais de três meses na instituição, não observei nada de diferente, após a política de cotas raciais." (P2)

"Mudou a forma de seleção dos candidatos. Hoje se utiliza, no ato da inscrição, a opção, informação, se o candidato pertence à raça favorecida pelas cotas. Isto causa errôneas interpretações, algumas vezes. [...] Não vejo alterações nas práticas pedagógicas.” (P3)

"Pelo pouco tempo que atuei no Curso Técnico em Agropecuária não foi possível perceber alguma mudança. No entanto, entre os alunos, nota-se que falta informação, as opiniões formadas são superficiais dos vários lados dos debates, tendenciosas, talvez pela condição do pouco esclarecimento sobre a política. Nesse sentido, é papel da instituição e dos professores sanar estas dúvidas, relatando com veracidade os benefícios e os problemas da política de cotas raciais." (P5)

\section{"Acredito que não houve nenhuma mudança." (P6)}

"Não observei durante o período, na instituição, nenhuma mudança significativa potencializada a partir das cotas raciais. Apenas presenciei em uma das reuniões pedagógicas semanais, uma palestra abordando o tema, ministrado por uma estudante de doutorado, que também foi articuladora do governo federal, para implantar essa política no contexto da educação nacional. Foi nesse momento que entendi que não era necessário ser negro de cor absoluta para ser incluído nessa política, mas sim possuir o sangue da raça negra através da descendência, assim como os brasileiros pardos e os demais que se declaram de origem familiar negra." (P7)

Conforme pôde-se verificar, os docentes não observaram quaisquer mudanças nas práticas dos docentes do curso após a implantação do sistema de cotas raciais. Apesar disso, um dos docentes destacou mudança na forma de seleção dos discentes e outro ressaltou sua experiência em uma reunião pedagógica.

Embora não tenham sido destacadas mudanças no curso, destaca-se a necessidade de uma prática que seja mais democrática e participativa, permitindo o desenvolvimento de ações dinâmicas, coletivas e mais articuladas com as relações étnico-raciais (Gomes, 2011).

Com relação à seleção dos alunos, conforme consulta realizada na secretaria da instituição, verificou-se que no ano de 2013 ingressaram cinco alunos cotistas raciais. Em 
2014 esse número passou para 19. Destaca-se que um sistema de conferência destes dados ainda está por ser implantado, o que torna esses números pouco precisos.

\section{Considerações finais}

Concernente às mudanças na prática pedagógica, após a implantação da política de cotas raciais, com ênfase na população negra, os estudos permitiram constatar que os docentes dividem-se entre posições favoráveis e contrárias à política. Ainda foi possível verificar que a criação do sistema de cotas para negros não impulsionou a modificação das práticas pedagógicas desenvolvidas pelos docentes ou pela instituição, na visão destes. Entretanto, estes souberam elencar práticas que se aproximam ou se distanciam da política.

Frente a esta constatação, sugere-se que os docentes e a própria instituição invista na criação de espaços que favoreçam o diálogo sobre as diferenças e problematizem as desigualdades existentes entre negros e brancos no âmbito educacional. Nesse sentido, como forma de contribuir para a mudança nas práticas pedagógicas, uma estratégia viável envolveria a formação continuada dos docentes, com o intuito de desconstruir e reconstruir concepções teóricas, rever conceitos e elaborar alternativas que contribuam para a qualificação do ensino.

Entre as opções de formação continuada, sugere-se a realização de grupos de debate, seminários, palestras, minicursos e socialização de experiências entre docentes, discentes e pesquisadores da área de outras instituições de ensino, bem como a implantação de cursos criados com a justificativa de que "a maioria dos docentes que atuam nos espaços institucionais de educação profissional, técnica e tecnológica, não possuem formação inicial específica para docência, fazendo-se necessária a oferta de cursos que atendam essa peculiaridade" (IFFarroupilha, 2014, p. 1) e com a oferta desse curso o comprometimento "com o fortalecimento de uma cultura do valor do trabalho, superando o histórico de fragmentação, improviso e insuficiência de formação pedagógica presente nas práticas de muitos docentes da educação profissional" (IFFarroupilha, 2014, p. 2).

Pondera-se que ao educar, o profissional deve levar em conta as diferenças e as desigualdades sociais, auxiliando os alunos a desconstruir o ambiente de sala de aula como um espaço de reprodução de práticas discriminatórias. Para tanto, faz-se necessário um repensar coletivo de todos educadores, atentando para as questões étnico-raciais e construindo uma prática pedagógica contextualizada.

\section{Referências}

AKKARI, Abdeljalil, SANTIAGO, Mylene Cristina. A gestão da diversidade cultural no contexto educacional brasileiro. Revista Educação em Questão, v. 38, n. 24, 2010, p. 933.

ALVES, Denise de Oliveira, CANTERLE, Simone Bianchini. A espistemologia de professores e professoras sobre o processo de construção do conhecimento em alunos com necessidades educacionais especiais - implicações educativas. Disponível em <http://www.sicoda.fw.uri.br/revistas/artigos/1_5_48.pdf> Acesso em 5 out. 2012. 
AMORIM, Roseane Maria de. O negro(a) na sociedade brasileira ontem e hoje: o papel das categorias raça, etnia e classe social para a educação escolarizada. Revista Lugares de Educação, v. 1, n. 1, 2011, p. 87-106.

ARAÚJO, Janine Plaça, SCHMIDT, Andréia. A inclusão de pessoas com necessidades especiais no trabalho: a visão de empresas e de instituições educacionais especiais na cidade de Curitiba. Revista Brasileira de Educação Especial, v. 12, n. 2, 2006, p. 241-254.

BAYMA, Fátima. Reflexões sobre a constitucionalidade das cotas raciais em universidades públicas no Brasil: referências internacionais e os desafios pós-julgamento das cotas. Revista Ensaio: Avaliação e Políticas Públicas em Educação, v. 20, n. 75, 2012, p. 325-346.

BRASIL. Experiências educacionais inclusivas: Programa Educação Inclusiva: direito à diversidade. Ministério da Educação, Secretaria de Educação Especial. Brasília, 2006.

BRASIL. Lei n. 12.288, de 20 de julho de 2010. Institui o estatuto de igualdade racial. Disponível em <http://www.planalto.gov.br/ccivil_03/_Ato2007-2010/2010/Lei/L12288. $\mathrm{htm}>$. Acesso em 7 fev. 2014.

BRASIL. Lei $n$. 12.711, de 29 de agosto de 2012. Dispõe sobre o ingresso nas universidades federais e nas instituições federais de ensino técnico de nível médio e dá outras providências. Disponível em <http://www.planalto.gov.br/ccivil_03/_ato20112014/2012/lei//12711.htm>. Acesso em 20 fev. 2014.

BRASIL. Lei n. 13.694, de 19 de janeiro de 2011. Institui o estatuto da igualdade racial e dá outras providências. Disponível em <http://www.al.rs.gov.br/filerepository/repLegis/ arquivos/13.694.pdf>. Acesso em 22 fev. 2014.

BRASIL. Pesquisas registram a desigualdade racial nos sistemas de ensino. Disponível em <http://portal.mec.gov.br/index.php?ltemid=86\&catid=202\&id=13406:pesquisas-regis tram-a-desigualdade-racial-nos-sistemas-de-ensino\&option=com_content\&view=article> Acesso em 10 ago. 2014.

CORDEIRO, Maria José de Jesus Alves. Cotas no ensino superior: ação de resistência contra o racismo e de ascensão social de negros e indígenas. Revista de Ciências Humanas, v. 12, n. 2, 2012, p. 357-369.

DOMINGUES, Petrônio. Ações afirmativas para negros no Brasil: o início de uma reparação histórica. Revista Brasileira de Educação, v. 29, 2005, p. 164-176.

EMERICH, Daisy Ribas. A percepção dos professores sobre o sistema de cotas para negros da Universidade Estadual de Mato Grosso do Sul - Curso de Pedagogia de Dourados (2004-2008). 81f. Campo Grande: UCDB, 2011. Dissertação (mestrado em Educação). Pós-Graduação em Educação. Universidade Católica Dom Bosco.

EMERICH, Daisy Ribas. A percepção dos professores do curso de pedagogia do município de Dourados sobre o sistema de cotas para negros no período de 2004 a 2008 na Universidade Estadual de Mato Grosso do Sul. ENCONTRO NACIONAL DE DIDÁTICA E PRÁTICAS DE ENSINO, 16, 2012. Anais ... Campinas: Unicamp, 2012.

GIL, Antônio Carlos. Como elaborar projetos de pesquisa. São Paulo: Atlas, 2007.

GLAT, Rosana, FERNANDES, Edicléa Mascarenhas. Da educação segregada à educação inclusiva: uma breve reflexão sobre os paradigmas educacionais no contexto da educação especial brasileira. Revista Inclusão, v. 1, n. 1, 2005, p. 35-39.

GOMES, Nilma Lino. Diversidade étnico-racial, inclusão e equidade na educação brasileira: desafios, políticas e práticas. Revista Brasileira de Política e Administração da Educação, v. 27, n. 1, 2011, p. 109-121. 
GOMES, Nilma Lino. Educação e relações raciais: refletindo sobre algumas estratégias de atuação. In: MUNANGA, Kabengele. Superando o racismo na escola. Brasília: MEC, Secretaria de Educação Continuada, Alfabetização e Diversidade, 2005, p. 143-154.

IFF. Projeto pedagógico do curso de especialização em docência na educação profissional técnica e tecnológica. Alegrete: IFF, 2014.

INEP. $\mathrm{Na}$ rede pública, $17 \%$ abandonam 0 ensino médio. Disponível em <http://portal.inep.gov.br/rss_censo-escolar/-/asset_publisher/oV0H/content/id/19775>.

Acesso em 11 ago. 2014.

IPEA. Retrato das desigualdades de gênero e raça. Brasília: Ipea, 2011.

QUEIROZ, Delcele Mascarenhas, SANTOS, Jocélio Teles dos. Sistema de cotas: um debate - dos dados à manutenção de privilégios e de poder. Educação \& Sociedade, v. 27, n. 96, 2006, p. 717-737.

SANCHES, Isabel, TEODORO, António. Da integração à inclusão escolar: cruzando perspectivas e conceitos. Revista Lusófona de Educação, v. 8, 2006, p. 63-83.

SÁNCHEZ, Pilar Arnaiz. A educação inclusiva: um meio de construir escolas para todos no século XXI. Inclusão: Educação Especial. Secretaria de Educação Especial, v. 1, n. 1, 2005, p. 7-18.

SANTOS, Lorene dos, SIMAN, Lana Mara de Castro. O que dizem os professores sobre o sistema de cotas para negros nas universidades públicas. História \& Ensino, v. 14, 2008, p. 95-114.

TOZETTO, Susana Soares, GOMES, Thaís de Sá. A prática pedagógica na formação docente. Reflexão e Ação, v. 17, n. 2, 2009, p. 181-96.

UFBA. Ações afirmativas na universidade pública: o caso da UFBA. Salvador: Centro de Estudos Afro-Orientais, 2005.

UNICEF. O direito de ser adolescente: oportunidade para reduzir vulnerabilidades e superar desigualdades. Brasília: Unicef, 2011.

Carmen Terezinha Maciel Alende é especialista em Docência na Educação Profissional Técnica e Tecnológica pelo Instituto Federal Farroupilha - campus Alegrete.

Endereço: Rua Colômbia, 131 - 97544-000 - Alegrete - RS - Brasil.

E-mail: carmen.alende@yahoo.com.br.

Mário Augusto Correia San Segundo é professor no Instituto Federal Farroupilha campus Alegrete.

Endereço postal completo: RS-377 - Km 27 - Passo Novo - 97555-000 - Alegrete RS - Brasil.

E-mail: mario.segundo@iffaroupilha.edu.br.

Recebido em 29 de janeiro de 2015.

Aceito em 14 de abril de 2015. 